\title{
Article \\ Evaluation of Prediction Models for the Physical Properties in Fire-Flooding Exhaust Reinjection Process
}

\author{
Yong Wang ${ }^{1,2, * \mathbb{C}}$, Mingliang Chang ${ }^{1}$, Long Chen ${ }^{3}$, Shouxi Wang ${ }^{1, *}$, Shihao Fan ${ }^{1}$ and Dongyang Hua ${ }^{1}$ \\ 1 College of Petroleum Engineering, Xi'an Shiyou University, Xi'an 710065, China; ml_chang@126.com (M.C.); \\ Shihao_Fan@126.com (S.F.); huady@cnooc.com.cn (D.H.) \\ 2 State Key Laboratory of Oil and Gas Reservoir Geology and Exploitation (Southwest Petroleum University), \\ Southwest Petroleum University, Chengdu 610500, China \\ 3 Research Institute of Engineering Technology, Xinjiang Petroleum Corporation, China National Petroleum \\ Corporation, Karamay 834000, China; cyycl@petrochina.com.cn \\ * Correspondence: wangyong@xsyu.edu.cn (Y.W.); swang@xsyu.edu.cn (S.W.)
}

check for updates

Citation: Wang, Y.; Chang, M.; Chen, L.; Wang, S.; Fan, S.; Hua, D. Evaluation of Prediction Models for the Physical Properties in Fire-Flooding Exhaust Reinjection Process. Energies 2022, 15, 562. https://doi.org/10.3390/en15020562

Academic Editor: Attilio Converti

Received: 25 October 2021

Accepted: 2 January 2022

Published: 13 January 2022

Publisher's Note: MDPI stays neutral with regard to jurisdictional claims in published maps and institutional affiliations.

Copyright: (C) 2022 by the authors. Licensee MDPI, Basel, Switzerland. This article is an open access article distributed under the terms and conditions of the Creative Commons Attribution (CC BY) license (https:// creativecommons.org/licenses/by/ $4.0 /)$.

\begin{abstract}
The reinjection of the fire-flooding exhaust is a novel disposal process for handling the exhaust produced by the in-situ combustion technology. For reasonable process design and safe operation, it is of great significance to select an optimum property calculation method for the fireflooding exhaust. However, due to the compositional particularity and the wide range of operating parameters during reinjection, the state equations in predicting the exhaust properties over the wide range of operating parameters have not been studied clearly yet. Hence, this paper investigates the applicability of several commonly-used equations of state, including the Soave-Redlich-Kwong equation, Peng-Robinson equation, Lee-Kesler-Plocker equation, Benedict-Webb-Rubin-Starling equation, and GERG-2008 equations. Employing Aspen Plus software, the gas densities, compressibility factors, volumetric coefficients, and dew points for five exhaust compositions are calculated. In comparison with the experimental data comprehensively, the result indicates that the Soave-RedlichKwong equation shows the highest precision over a wide range of temperature and pressure. The mean absolute percentage error for the above four parameters is $3.84 \%, 5.17 \%, 5.53 \%$, and $4.33 \%$, respectively. This study provides a reference for the accurate calculation of the physical properties of fire-flooding exhausts when designing and managing a reinjection system of fire-flooding exhaust.
\end{abstract}

Keywords: fire-flooding exhaust; reinjection process; equations of state; physical properties; $M A P E$

\section{Introduction}

Heavy oil is abundant but difficult to exploit. To improve the production of heavy oil reservoirs, some enhanced oil recovery (EOR) methods [1,2] have been adopted, such as steam flooding [3], high-pressure nitrogen flooding [4], $\mathrm{CO}_{2}$ flooding [5], fire flooding [6], microbial technology [7], and so on. Among them, taking the technical advantages of efficient oil displacement, low unit thermal cost, and wide applicability, the fire flooding technology is one of the most effective and promising ways to improve the thermal recovery of heavy-oil resources [8]. By combusting the air underground, the heat and mixed gas generated push the heavy oil from the gas injection well to the production well to realize short-distance displacement of heavy oil [9].

However, the combustion of heavy oil produces a large amount of exhaust gas, named fire-flooding exhaust, which contains both valuable and harmful components, such as methane, ethane, carbon dioxide, hydrogen sulfide, nitrogen, hydrogen, oxygen, etc. [10,11]. Table 1 compares the composition of fire-flooding exhausts with other greenhouse gasses referenced from published literature [12-18], including acid gas and flue gas. It can be seen that the composition of fire-flooding exhaust is considerably different from the other gases listed. Compared with the acid gas, the content of $\mathrm{CO}_{2}$ and $\mathrm{H}_{2} \mathrm{~S}$ in the fire-flooding exhaust is lower. However, the latter contains much $\mathrm{N}_{2}$ and other trace components. Compared 
with flue gas, being equivalent in the content of $\mathrm{N}_{2}$ and $\mathrm{CO}_{2}$, the fire-flooding exhaust has light hydrocarbons, $\mathrm{H}_{2} \mathrm{O}$, and trace amount of $\mathrm{O}_{2}, \mathrm{H}_{2} \mathrm{~S}, \mathrm{H}_{2}$, and $\mathrm{CO}$. It is conceivable that, with increasingly strict controls on environmental protection globally, how to efficiently and safely handle the exhaust gas which is produced by the fire flooding will become a key factor in restricting its worldwide application.

Table 1. Comparison of the components of acid gas, flue gas, and fire-flooding exhaust (unit: mol \%).

\begin{tabular}{|c|c|c|c|c|c|c|c|c|c|c|}
\hline Gas & $\mathrm{CO}_{2}$ & $\mathbf{N}_{2}$ & $\mathrm{O}_{2}$ & $\mathrm{H}_{2}$ & $\mathrm{H}_{2} \mathrm{O}$ & $\mathrm{H}_{2} \mathrm{~S}$ & $\mathrm{C}_{1}$ & $\mathrm{C}_{2}$ & Others & Notes \\
\hline Acid gas No.1 & 86 & & & & & 10 & & & & $\begin{array}{c}\text { Acheson (Canada) } \\
\text { [12] }\end{array}$ \\
\hline Acid gas No.2 & 65 & & & & & 35 & & & & $\begin{array}{c}\text { Lisbon (America) } \\
\text { [12] }\end{array}$ \\
\hline Acid gas No.3 & 100 & & & & & & & & & Salah (Algeria) [12] \\
\hline Flue gas No.1 & 15.6 & 84.4 & & & & & & & & $\begin{array}{c}\text { Combustion gas in } \\
\text { a thermal power } \\
\text { plant [13] }\end{array}$ \\
\hline Flue gas No.2 & 14.2 & 80.8 & 5 & & & & & & & Reference [13] \\
\hline Flue gas No.3 & 18.41 & 75.28 & 4.71 & & 1.6 & & & & & Reference [14] \\
\hline Flue gas No.4 & 10 & 80 & 5 & & & 5 & & & & Reference [15] \\
\hline Flue gas No.5 & $5-9$ & $49-57$ & $8-12$ & & saturation & & & & & Reference [16] \\
\hline $\begin{array}{l}\text { Fire-flooding } \\
\text { exhaust No.1 }\end{array}$ & 15.27 & 64.85 & 1.14 & & & & 17.61 & & & $\begin{array}{l}\text { Liaohe Oilfield, } \\
\text { China [17] }\end{array}$ \\
\hline $\begin{array}{l}\text { Fire-flooding } \\
\text { exhaust No.2 }\end{array}$ & 13.29 & 73.6 & 0.35 & & & & 11.87 & 0.36 & $C_{3}+: 0.53$ & \\
\hline $\begin{array}{l}\text { Fire-flooding } \\
\text { exhaust No.3 }\end{array}$ & 13.56 & 76.76 & 0.97 & 0.49 & 2.58 & 0.1 & 4.38 & 0.38 & $\begin{array}{l}C_{3}+: 1.01 \\
\text { CO: } 0.15\end{array}$ & $\begin{array}{l}\text { Xinjiang Oilfield, } \\
\text { China [18] }\end{array}$ \\
\hline
\end{tabular}

Some technologies-including burning [19], desulfurization [20], pressure swing adsorption [21], $\mathrm{CO}_{2}$ separation [22], etc.- have been applied to effectively treat the harmful components in the fire-flooding exhaust. Unfortunately, the valuable hydrocarbon resource in it is wasted meanwhile. To improve the situation, like the acid gas injection procedure [23], a novel treatment strategy called the 'fire-flooding exhaust reinjection process' was proposed in an oilfield in northwest China [18]. In the proposed procedure, the fireflooding exhaust will be dehydrated, compressed, and injected back into another proper oil reservoir, achieving zero emissions of harmful gases. Meanwhile, by adopting the principle of flue gas flooding [24], the novel process will make full use of the fire-flooding resource to enhance the oil recovery of the selected oil layers. Hence, it can be regarded as a promising method to realize multiple goals simultaneously, including waste handling, carbon capture and utilization, heavy oil enhancement, etc.

In the process, the exhaust needs to undergo dehydration, compression, pipeline transportation, cooling, and reinjection. Accordingly, the pressure will gradually increase to be higher than $20 \mathrm{MPa}$ from the wellhead condition, with the temperature fluctuating over $160 \mathrm{~K}$ meanwhile, as shown in Figure 1 [18]. Together with the unique composition of fireflooding exhausts, getting the physical properties accurately during the whole operation is a major problem to be solved for reinjection engineering. 


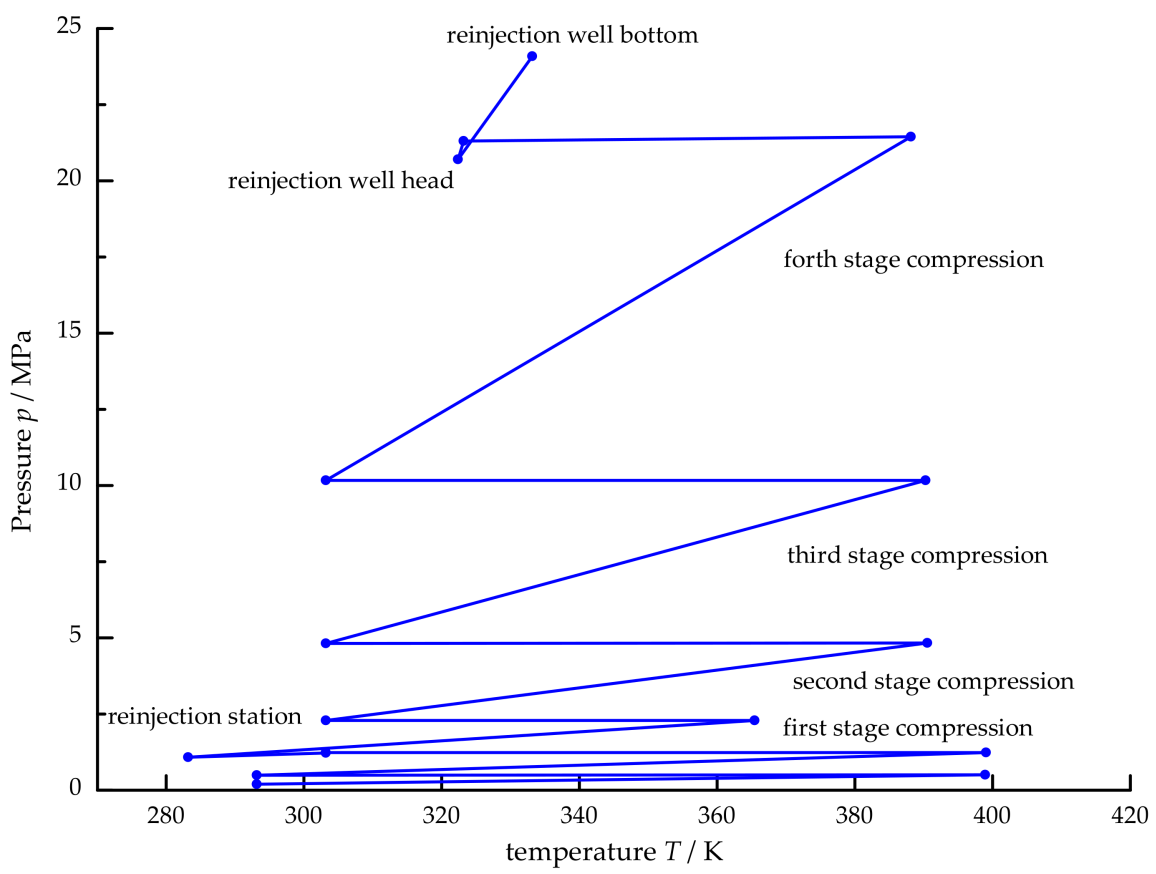

Figure 1. Temperature and pressure change during the proposed reinjection process of the fireflooding exhaust.

Simulation is the most economical and intuitive research method for oil and gas processing and transporting systems [25]. For the reinjection project of the fire-flooding exhaust, it can realize the prediction of the gas physical properties under different operating conditions, thus contributes to the precise design and safe operation. There is a number of chemical simulation software nowadays-such as Aspen HYSYS, Aspen Plus, Pro II, UniSim Design, etc.-which includes a variety of physical property calculation methods to achieve the above simulation goals. The first and most important step in numerical simulation is to select a precise physical property calculation method, which should provide a good approximation of the properties over the wide process ranges of pressure, temperature and composition [26]. Whether the prediction equation is suitable or will not directly affect the reliability of the calculation results [27].

Some well-known equations of state (EoS) - such as the Peng-Robinson (PR) equation, the Soave-Redlich-Kwong (SRK) equation, the Lee-Kesler-Plocker (LKP) equation, the Benedict-Webb-Rubin-Starling (BWRS) equation, etc.- -have been used or modified to study the natural gas treatment, acid gas treatment, reinjection, and other energy fields. Zhou et al. [28] combined PR and Patel-Teja equation to predict the densities and viscosities of the acid gas during an acid gas reinjection process. Wang et al. [29] developed the PengRobinson-cubic-plus-association (PR-CPA) EoS with a pseudo-chemical reaction approach to calculate the solubility of acid gases in aqueous alkanolamines solutions. Based on the SRK equation, Hussain [15] established a HYSYS model to perform a feasibility analysis of recovering carbon dioxide from flue gas. The SRK equation was also used to calculate the saturation pressure of the crude oil and its mixtures with pure and impure $\mathrm{CO}_{2}$ by Pereira et al. [30]. Modekurti et al. [24] conducted a dynamic modeling of a multistage $\mathrm{CO}_{2}$ compression system, in which the LKP method was used in the property prediction for the compression section. Adom et al. [31] applied the BWRS model to predict the compressibility factor, enthalpy, and heat leakage at various pressures for determining the factors which affect the BOG in typical LNG tanks of different capacities. Combing the PR and the eNRTL activity coefficient equation, Wan et al. [32] conducted an acid gas-chemical solvent model to simulate the desulfurization and decarbonization process of a natural gas treatment plant. 
Research results reveal that the accuracy of calculation methods for physical property forecasting closely relates to the composition and operation condition studied. A comparative study of different prediction models is helpful to master their applicability in different scenarios, which benefits in model selection. W. Yan et al. [33] made a comparative study of non-cubic models (PC-SAFT and BWRS) and cubic models (SRK and PR) in several important aspects related to PVT modeling of reservoir fluids. The result shows that the non-cubic models are clearly advantageous in density calculation of pure components and some HP and HT fluids. Compared with the NIST results, M. Bertini et al. [34] evaluated 10 property methods for pure and mixture of $\mathrm{CO}_{2}$ for power cycles, including the cubic-type, virial-type, Helmholtz-type, and SAFT-type. G.D. Marcoherardino et al. [35] conducted an analysis of the performance of five EoSs on $\mathrm{CO}_{2}+\mathrm{C}_{6} \mathrm{~F}_{6}$, revealing that although all equations converge at low temperature, the big difference and non-convergence occurs at higher temperatures. The region close to the critical point is the most difficult to be modeled. Varzandeh [36] compared the GERG-2008 with other cubic and non-cubic EoS in calculation of the phase equilibrium and physical properties of natural gas related systems. A similar study was carried out by Yuan et al. [27]. After conducting a comprehensive comparison and analysis among the SRK, PR, and GERG-2008 equations, the GERG-2008 equation was recommended as the basis for the property calculation in the natural gas liquefaction processes. Many similar studies exist that are not enumerated here.

However, according to the papers published, there is little literature studying the application of the above EoSs in predicting the physical properties of the fire-flooding exhaust. Considering the compositional singularity of the fire-flooding exhaust and the wide range of operating parameters accompanied with the reinjection procedure, the accuracy of property calculation methods is unclear yet. Since every model has its applicable boundary, the purpose of this research is to investigate the application of some commonlyused EoSs in predicting the physical properties of the fire-flooding exhaust within a wide range of pressure and temperature. The EoSs evaluated in this work include the PR, the SRK, the LKP, the BWRS, and the GERG-2008 equations. Using a HPHT physical property analyzer and the Aspen Plus software, the physical properties were detected and predicted, including the gas densities, compressibility factors, volumetric coefficients, and dew point temperatures for five exhaust compositions which were collected from a real oilfield. A comprehensive comparison and analysis between the experimental data and the calculated value for the five equations was then conducted. This work is helpful to select a precise property calculation method when simulating and designing a reinjection system which is used to reduce the emission of the harmful gas produced by the fire flooding process. It can be applied in the simulation of other waste treatment processes, too.

\section{Equations of State to Be Evaluated}

\subsection{Soave-Redlich-Kwong EoS}

Redlich and Kwong [37] proposed a modified cubic EoS with two parameters, which obtained satisfactory results at the pressure above the critical temperature. A modification of this equation was developed by Soave [38], thus the SRK equation was obtained. It was the first EoS to be associated with the acentric factor and could be applied to all non-polar substances [39], particularly for multicomponent mixtures. The equation is given below:

$$
\begin{gathered}
p=\frac{R T}{v-b}-\frac{a(T)}{v(v+b)} \\
a(T)=\alpha(T) 0.42747 R^{2} T_{c}^{2} / p_{c} \\
b=0.08664 R T_{c} / p_{c} \\
\alpha(T)=\left[1+m\left(1-\left(T / T_{c}\right)^{0.5}\right)\right]^{2} \\
m=0.480+1.5741 \omega-0.1715 \omega^{2}
\end{gathered}
$$

Where $p, R, T$, and $v$ is the pressure, gas constant, temperature, and molar volume respectively, $a$ and $b$ are parameters of the EoS, only related to physical properties, $T_{c}$ is the critical temperature, and $\omega$ is the acentric factor. 
For mixtures, mixing rules are expressed as

$$
\begin{gathered}
a=\sum_{i} \sum_{j} x_{i} y_{j}\left(a_{i} a_{j}\right)^{0.5}\left(1-k_{i j}\right) \\
b=\sum_{i} y_{i} b_{i} \\
T_{c m}=\sum_{i} x_{i} T_{c i} \\
p_{c m}=\sum_{i} x_{i} p_{c i}
\end{gathered}
$$

where $x_{i}$ and $x_{j}$ is the molar fractions of components $i$ and $j, T_{c m}$ and $p_{c m}$ is the critical temperature and critical pressure of the mixture, respectively, $a_{i}$ and $b_{i}$ are the pure component parameters obtained from Equation (1), and $k_{i j}$ is the binary interaction parameter of the SRK equation.

\subsection{Peng-Robinson EoS}

The SRK equation is not accurate in predicting liquid density. For hydrocarbon components (except for the methane), the predicted liquid density is generally smaller than the experimental data. To further improve the prediction accuracy of physical parameters and phase equilibrium, Peng and Robinson [40] developed a two-constant EoS based on the Soave's model. It showed great advantages in predicting liquid phase density. The equation is given below as

$$
\begin{gathered}
p=\frac{R T}{v-b}-\frac{a(T)}{v(v+b)+b(v-b)} \\
a(T)=0.45724 \alpha(T) R^{2} T_{c}^{2} / p_{c} \\
b(T)=0.07780 R T_{c} / p_{c} \\
\alpha(T)=\left[1+k\left(1-\left(T / T_{c}\right)^{0.5}\right)\right]^{2}
\end{gathered}
$$

where the notation declarations and mixing rules are consistent with the SRK equation.

\subsection{Lee-Kesler-Plocker EoS}

The LKP equation is a modified LK equation proposed by Plocker, Knapp, and Prausnitz [41]. It retained the prototype of the LK equation but modified the mixing rule. The LKP equation is applicable to the liquid phase, especially with good accuracy in the calculation of the physical properties of hydrocarbons. It was deemed to be the best method for forecasting the gas thermophysical properties [42]. The equation is expressed as

$$
\begin{gathered}
Z=Z^{(0)}+\frac{\omega}{\omega^{(r)}}\left(Z^{(r)}-Z^{(0)}\right) \\
Z=\frac{p_{r} v_{r}}{T_{r}}=1+\frac{B}{v_{r}}+\frac{C}{v_{r}^{2}}+\frac{D}{v_{r}^{5}}+\frac{c_{4}}{T_{r}^{3} v_{r}^{2}}\left(\beta+\frac{\gamma}{v_{r}^{2}}\right) \exp \left(-\frac{\gamma}{v_{r}}\right) \\
B=b_{1}-\frac{b_{2}}{T_{r}}-\frac{b_{3}}{T_{r}^{2}}-\frac{b_{4}}{T_{r}^{3}} \\
C=c_{1}-\frac{c_{2}}{T_{r}}+\frac{c_{3}}{T_{r}^{3}} \\
D=d_{1}+\frac{d_{2}}{T_{r}}
\end{gathered}
$$

where $Z$ is the compression factor, 0 and $r$ represents the simple and reference fluid parameters, respectively, and $b_{1} \sim b_{4}, c_{1} \sim c_{4}, d_{1}, d_{2}, \beta$, and $\gamma$ are model constants. 
For mixtures, mixing rules are expressed as

$$
\begin{gathered}
T_{c m} v_{c m}^{0.25}=\sum_{i} \sum_{j} x_{i} x_{j} v_{c i j}^{0.25} T_{c i j} \\
v_{c m}=\sum_{i} \sum_{j} x_{i} x_{j} v_{c i j} \\
\omega_{m}=\sum_{i} x_{i} \omega_{i} \\
T_{c i j}=\left(T_{c i} T_{c j}\right)^{0.5} k_{i j} \\
v_{c i j}=\frac{1}{8}\left(v_{c i}^{1 / 3}+v_{c j}^{1 / 3}\right)^{3}
\end{gathered}
$$

where $k_{i j}$ represents the binary interaction parameter of the LKP equation.

\subsection{Benedict-Webb-Rubin-Starling EoS}

To expand the application range and improve the accuracy at high pressure and low temperature, Benedict-Webb-Rubin conducted an 8-parameters method which was applied in a gas-liquid system in 1940, called BWR equation [43]. Compared with the SRK and PR method, the equation performed high accuracy in predicting the thermophysical properties of light hydrocarbons and their mixtures. However, it had poor adaptability to the mixtures with more non-hydrocarbon gases, heavier hydrocarbon components, and lower temperatures $\left(T_{r}<0.6\right)$. Combining the thermodynamic data of $C_{1} \sim C_{8}$ alkanes, Staring and Powers [44], Starling and Han [45], updated the BWR model to an 11-constant equation, namely the BWRS equation, which showed high prediction accuracy for the physical properties of hydrocarbon, $\mathrm{CO}_{2}, \mathrm{H}_{2} \mathrm{~S}$, and $\mathrm{N}_{2}$. The BWRS equation is given as

$$
\begin{aligned}
p=\rho R T+ & \left(B_{0} R T-A_{0}-\frac{C_{0}}{T^{2}}+\frac{D_{0}}{T^{3}}-\frac{E_{0}}{T^{4}}\right) \rho^{2}+\left(b R T-a-\frac{d}{T}\right) \rho^{3} \\
& +\alpha\left(a+\frac{d}{T}\right) \rho^{6}+\frac{c \rho^{3}}{T^{2}}\left(1+\gamma \rho^{2}\right) \exp \left(-\gamma \rho^{2}\right)
\end{aligned}
$$

where $A_{0}, B_{0}, C_{0}, D_{0}, E_{0}, \gamma, a, b, c, d$, and $\alpha$ are the parameters of BWRS equation of which form are shown in reference [44].

\subsection{GERG-2008 EoS}

As an international standard named ISO20765-2 [46], the GERG-2008 equation is the extension of the GERG-2004 model [47]. This equation covers 21 natural gas components, including $\mathrm{CH}_{4}, \mathrm{~N}_{2}, \mathrm{CO}_{2}, \mathrm{C}_{2} \mathrm{H}_{6}, \mathrm{C}_{3} \mathrm{H}_{8}, \mathrm{C}_{4} \mathrm{H}_{10}, \mathrm{I}_{-} \mathrm{C}_{4} \mathrm{H}_{10}, \mathrm{C}_{5} \mathrm{H}_{12}, \mathrm{I}_{-} \mathrm{C}_{5} \mathrm{H}_{12}, \mathrm{C}_{6} \mathrm{H}_{14}, \mathrm{C}_{7} \mathrm{H}_{16}$, $\mathrm{C}_{8} \mathrm{H}_{18}, \mathrm{C}_{9} \mathrm{H}_{20}, \mathrm{C}_{10} \mathrm{H}_{22}, \mathrm{H}_{2}, \mathrm{O}_{2}, \mathrm{CO}, \mathrm{H}_{2} \mathrm{O}, \mathrm{H}_{2} \mathrm{~S}$, He, and Ar. Being explicit in the Helmholtz free energy as a function of density, temperature, and composition, the GERG-2008 equation was constructed by fitting a large number of experimental data to obtain the regression coefficients. Furthermore, it has been improving and upgrading with more experimental data nowadays [48]. Hence, it showed excellent predictive performance in the gas phase, liquid phase, supercritical region, and vapor-liquid equilibrium states for mixtures of the components mentioned above, and was regarded as the most comprehensive calculation method in predicting natural gas thermophysical properties. However, for the fire-flooding exhaust, the precision has not been assessed and needs to be studied. The equation is expressed as

$$
a(\rho, T, \bar{x})=a^{o}(\rho, T, \bar{x})+a^{r}(\rho, T, \bar{x})
$$

Using the dimensionless form of Helmholtz free energy $\alpha=a /(R T)$, the following equation is deduced (note that $\alpha^{o}$ does not depend on $\delta$ and $\tau$ of the mixture but $\rho$ and T)

$$
\begin{aligned}
\alpha(\delta, \tau, \bar{x}) & =\alpha^{o}(\rho, T, \bar{x})+\alpha^{r}(\delta, \tau, \bar{x}) \\
\delta & =\rho / \rho_{r}, \tau=T / T_{r}
\end{aligned}
$$


The dimensionless form of the Helmholtz free energy for the ideal-gas mixture $\alpha^{o}$ is given by

$$
\alpha^{o}(\rho, T, \bar{x})=\sum_{i=1}^{N} x_{i}\left[\alpha_{o i}^{o}(\rho, T)+\ln x_{i}\right]
$$

The residual part of the Helmholtz free energy is expressed as

$$
\alpha^{r}(\delta, \tau, \bar{x})=\sum_{i=1}^{N} x_{i} \alpha_{o i}^{r}(\delta, \tau)+\sum_{i=1}^{N-1} \sum_{j=i+1}^{N} x_{i} x_{j} F_{i j} \alpha_{i j}^{r}(\delta, \tau)
$$

For mixtures, the mixture density and mixture temperature are given below as

$$
\begin{gathered}
\frac{1}{\rho_{r}(\bar{x})}=\sum_{i=1}^{N} x_{i}^{2} \frac{1}{\rho_{c i}}+\sum_{i=1}^{N-1} \sum_{j=i+1}^{N} 2 x_{i} x_{j} \beta_{v, i j} \gamma_{v, i j} \cdot \frac{x_{i}+x_{j}}{\beta_{v, i j}^{2} x_{i}+x_{j}} \cdot \frac{1}{8}\left(\frac{1}{\rho_{c i}^{1 / 3}}+\frac{1}{\rho_{c j}^{1 / 3}}\right)^{3} \\
T_{r}(\bar{x})=\sum_{i=1}^{N} x_{i}^{2} T_{c i}+\sum_{i=1}^{N-1} \sum_{j=i+1}^{N} 2 x_{i} x_{j} \beta_{T, i j} \gamma_{T, i j} \cdot \frac{x_{i}+x_{j}}{\beta_{T, i j}^{2} x_{i}+x_{j}}\left(T_{c i} \cdot T_{c j}\right)^{0.5}
\end{gathered}
$$

The detailed expressions involved in the above equations can be seen in reference [47].

The above property calculation methods have been embedded in the Aspen Plus software which can be used as a platform to analyze the accuracy of each EoS. In Aspen Plus, the above property methods are named as SRK, PENG-ROB, LK-PLOCK, BWRS, and GERG2008. In this paper, for the SRK equation, the PR equation, the LKP equation, and the BWRS equation, the binary interaction parameters of Knapp et al. [49] were used. The precision of the five models mentioned is analyzed by comparing the calculation results with the experimental data.

\section{Accuracy Analysis of the Calculation Models for the Physical Properties in the Fire-Flooding Exhaust Reinjection Process}

In order to find out the most precise physical equation among the five EoSs for the fireflooding exhaust reinjection process, a comparison between the experimental data and the calculated value under the same temperature and pressure for different physical properties is needed. In this study, the properties of five representative fire-flooding exhausts collected

\begin{tabular}{|c|c|c|c|c|c|c|c|c|c|c|}
\hline \multirow{2}{*}{ Sample Name } & \multicolumn{9}{|c|}{ Composition (mol\%) } & \multirow{2}{*}{ Analysis Method } \\
\hline & $\mathrm{CH}_{4}$ & $\mathrm{C}_{2} \mathrm{H}_{6}$ & $\mathrm{C}_{3} \mathrm{H}_{8}$ & $\mathrm{C} 4+$ & $\mathbf{N}_{2}$ & $\mathrm{CO}_{2}$ & $\mathrm{O}_{2}$ & $\mathrm{H}_{2}$ & $\mathrm{H}_{2} \mathrm{~S}$ & \\
\hline Sample 1 & 1.9 & 0.14 & 0.07 & 0.08 & 78.13 & 17.59 & 2.07 & - & 0.02 & \multirow{5}{*}{$\begin{array}{l}\text { PVT property } \\
\text { analysis }\end{array}$} \\
\hline Sample 2 & 3.08 & 0.22 & 0.11 & 0.074 & 80.4 & 15.2 & 0.25 & 0.53 & 0.088 & \\
\hline Sample 3 & 4.49 & 0.29 & 0.13 & 0.16 & 77.76 & 13.93 & 3.27 & - & 0.062 & \\
\hline Sample 4 & 5.61 & 0.36 & 0.16 & 0.2 & 79.22 & 13.98 & 1.15 & - & 0.088 & \\
\hline Sample 5 & 0.97 & 0.095 & 0.04 & 0.034 & 81.89 & 16.97 & 3.5 & - & 0.011 & \\
\hline
\end{tabular}
from an oilfield in the northwest China were detected. The gas compositions are shown in Table 2.

Table 2. Compositions of five fire-flooding exhaust samples.

The experimental data, including the densities, the compressibility factors, the volumetric coefficients and the dew point temperatures for the mentioned components above, is obtained through a high pressure (HP) and high temperature (HT) physical property analyzer of which parameters are shown in Table 3 . This equipment is particularly used to detect the physical properties and phase states of formation fluids. Combining the field operating parameters and the experimental condition, the tested pressure of 4-25 MPa was set, while the tested temperature contained $303.15 \mathrm{~K}, 333.15 \mathrm{~K}, 363.15 \mathrm{~K}$, and $393.15 \mathrm{~K}$. After the experimental testing, a total of 1351 valid experimental data was obtained, which was used for the model evaluation and analysis. 
Table 3. Equipment parameters used in this study.

\begin{tabular}{cc}
\hline Technical Indicators & Value \\
\hline Working pressure & $0-100 \mathrm{MPa}$ \\
Working temperature & From ambient temperature to $473.15 \mathrm{~K}$ \\
Pump capacity & $500 \mathrm{~mL}$ \\
Pump precision & $0.0001 \mathrm{~mL}$ \\
\hline
\end{tabular}

Some indicators are necessary for evaluating the performance of the prediction models. The common used includes the correlation coefficient (CC), the mean squared error (MSE), the mean absolute error $(M A E)$, the mean absolute percentage error (MAPE), the root mean square error (RMSE), the normalized root mean squared error (NRMSE), and the mean absolute range normalized error (MARNE) [50]. These indicators are defined as

$$
\begin{gathered}
C C=\frac{\operatorname{cov}\left(x^{\mathrm{cal}}, x^{\exp }\right)}{\sqrt{D\left(x^{\mathrm{cal}}\right) D\left(x^{\mathrm{exp}}\right)}} \\
M S E=\frac{1}{N} \sum_{i=1}^{N}\left(x_{i}^{\exp }-x_{i}^{\mathrm{cal}}\right)^{2} \\
M A E=\frac{1}{N} \sum_{i=1}^{N}\left|x_{i}^{\exp }-x_{i}^{\mathrm{cal}}\right| \\
\text { MAPE }=\frac{1}{N} \sum_{i=1}^{N} \mid \frac{x_{i}^{\mathrm{cal}}-x_{i}^{\exp } \mid}{x_{i}^{\exp } \mid \times 100 \%} \\
\text { RMSE }=\sqrt{\frac{1}{N} \sum_{i=1}^{N}\left(x_{i}^{\mathrm{cal}}-x_{i}^{\exp }\right)^{2}} \\
\text { NRMSE }=\frac{1}{\bar{x}^{\exp }} \sqrt{\frac{1}{N} \sum_{i=1}^{N}\left(x_{i}^{\mathrm{cal}}-x_{i}^{\exp }\right)^{2}} \\
\text { MARNE }=\frac{1}{N} \sum_{i=1}^{N} \frac{\left|x_{i}^{\mathrm{cal}}-x_{i}^{\exp }\right|}{\max \left(x_{i}^{\text {cal }}\right)} \times 100 \%
\end{gathered}
$$

where $x^{\mathrm{cal}}$ is the calculated value, $x^{\exp }$ is the experimental value, $N$ is the dataset size.

For different goals and data sets, the significance of every indicator-such as $M A E$, $M S E$, and RMSE-is not the same [51]. According to the similar literature published [30,52], in our work, the MAPE is employed as the main criterion to evaluate the accuracy of different prediction methods.

In the following paragraphs, Section 3.1 Sections 3.2-3.4 are the detailed comparison results between the calculated and the experimental data. Tables 4, 6, and 8 lists the comparison of gas densities, compressibility factors and volumetric coefficients for Sample 1 as an example, respectively. The comparison of dew point temperature for the five samples is illustrated from Figures 2-6. Tables 5, 7, 9, and 10 shows the prediction accuracy for each model in predicting the four properties, respectively. An overall summary was conducted in the Results. 


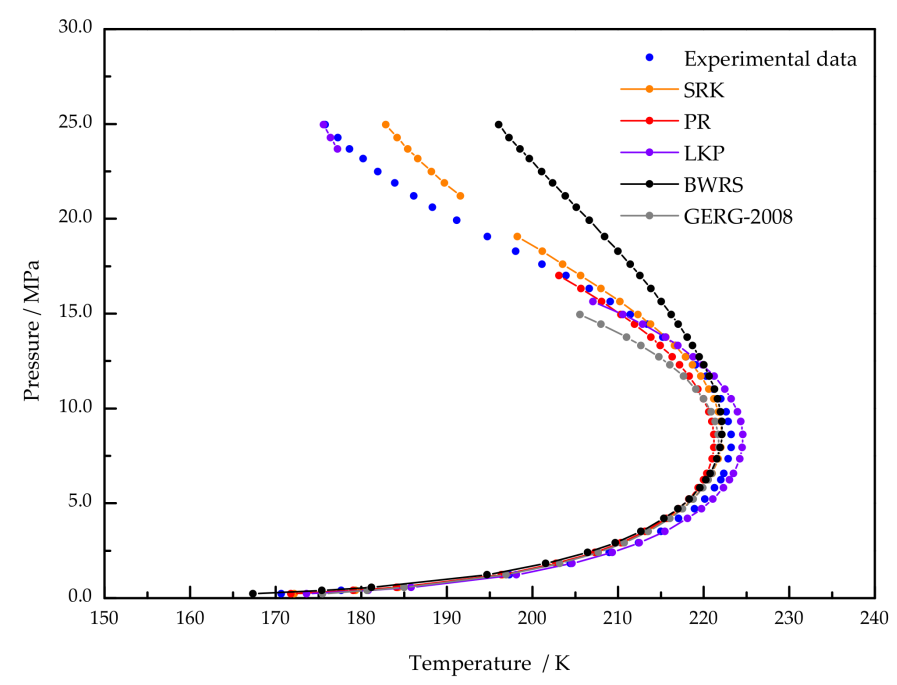

Figure 2. Experimental and calculation results of dew points for Sample 1.

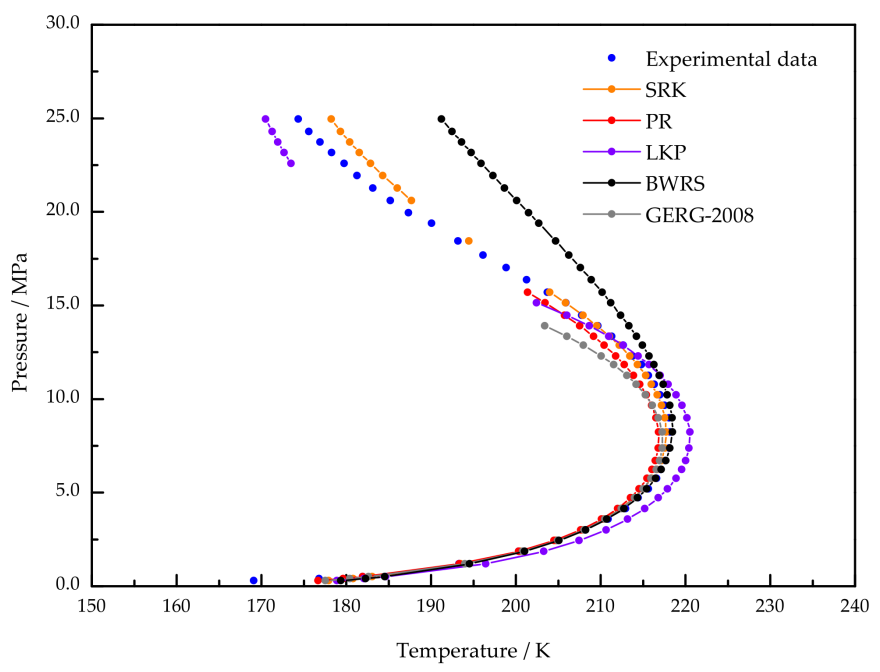

Figure 3. Experimental and calculation results of dew points for Sample 2.

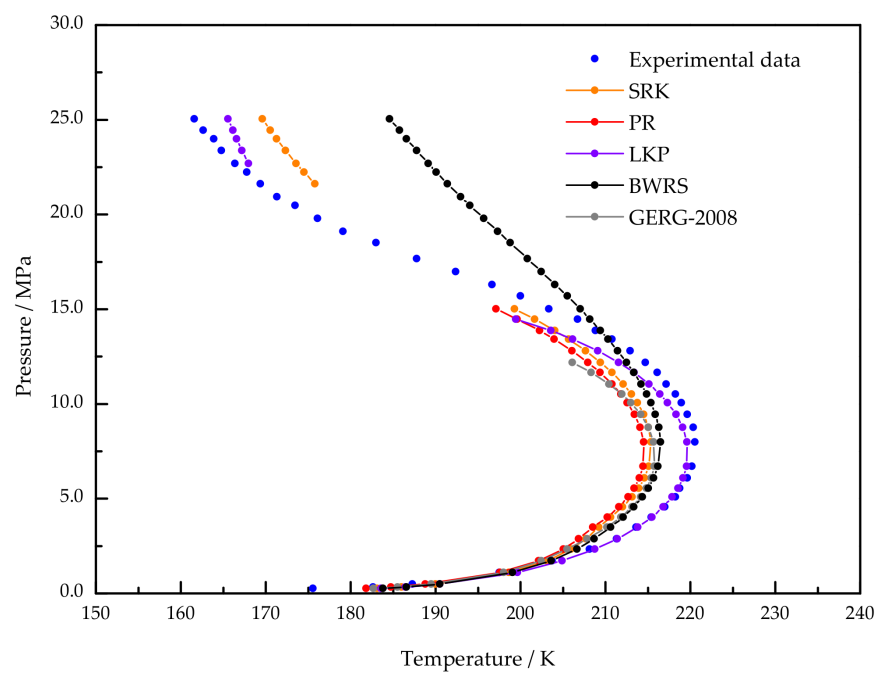

Figure 4. Experimental and calculation results of dew points for Sample 3. 


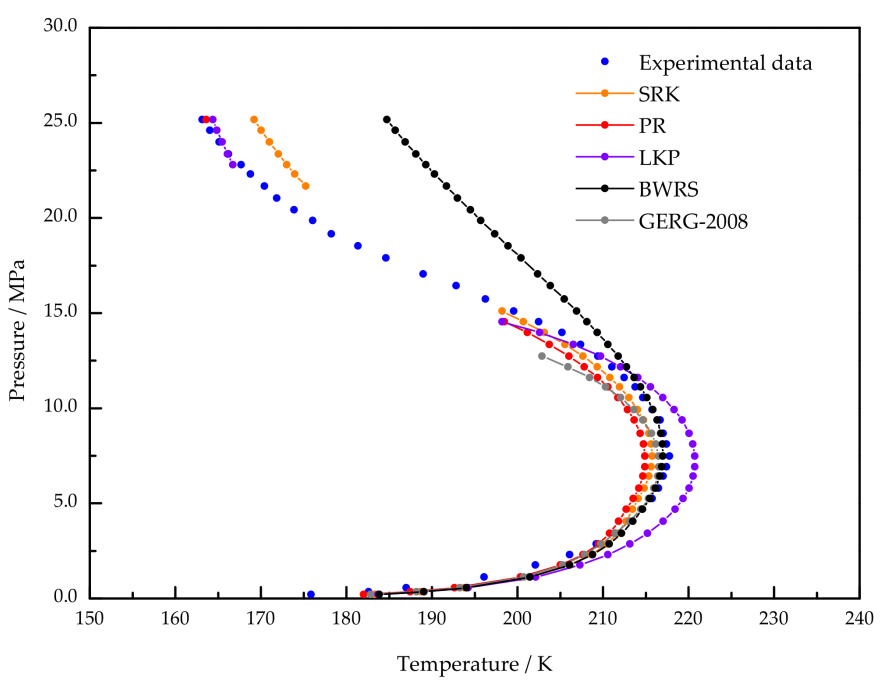

Figure 5. Experimental and calculation results of dew points for Sample 4.

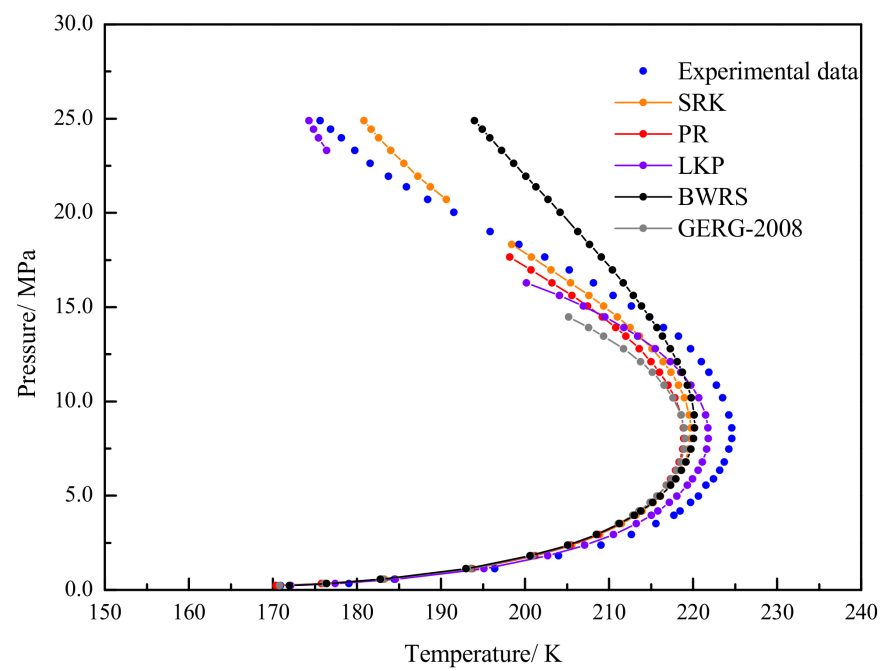

Figure 6. Experimental and calculation results of dew points for Sample 5.

\subsection{Accuracy Analysis of the Prediction Models for the Gas Density}

The density is the most important and fundamental property for process design. Using the Aspen Plus software, the densities of the collected fire-flooding exhausts were calculated by employing the five prediction models under the same conditions as the experiments. The total number of the experimental data for the five samples is 378. Table 4 shows the experimental and the calculation results of Sample 1 as an example. By comparing with the experimental data, Table 5 lists the prediction accuracies for each model. The comparison result shows that, the SRK equation performs the minimum overall MAPE in calculating gas density, followed by the BWRS equation. Although the PR equation shows the highest prediction accuracy for Sample 4 and 5, its overall prediction accuracy is the lowest among the five equations. In comparison, the calculation accuracy of the SRK equation is maintained at a relatively high level for the five sample compositions as a whole. Therefore, it can be considered that the SRK equation is the suitable model for predicting the density of fire-flooding exhausts during the reinjection process. 
Table 4. Experimental data and calculated results of the gas density for Sample 1.

\begin{tabular}{|c|c|c|c|c|c|c|c|}
\hline \multirow{2}{*}{\multicolumn{3}{|c|}{ Experimental Data }} & \multicolumn{5}{|c|}{ Calculated Results } \\
\hline & & & SRK & PR & LKP & BWRS & GERG-2008 \\
\hline$T(\mathrm{~K})$ & $p$ (MPa) & $\rho\left(\mathrm{kg} / \mathrm{m}^{3}\right)$ & \multicolumn{5}{|c|}{$\rho\left(\mathrm{kg} / \mathrm{m}^{3}\right)$} \\
\hline \multirow{11}{*}{303.15} & 24.040 & 280.818 & 287.1567 & 303.4508 & 296.5895 & 285.2223 & 295.9078 \\
\hline & 22.020 & 260.102 & 265.6166 & 280.0517 & 274.2284 & 264.7271 & 273.7772 \\
\hline & 20.000 & 238.235 & 245.3392 & 258.0877 & 253.0746 & 245.2787 & 252.7865 \\
\hline & 18.047 & 217.519 & 222.6385 & 233.5732 & 229.3109 & 223.3094 & 229.1533 \\
\hline & 16.027 & 194.501 & 199.0326 & 208.1689 & 204.5558 & 200.2309 & 204.488 \\
\hline & 14.007 & 171.483 & 175.4618 & 182.899 & 179.8466 & 176.9487 & 179.8341 \\
\hline & 11.919 & 147.315 & 151.2386 & 157.043 & 154.5195 & 152.7901 & 154.5381 \\
\hline & 9.899 & 121.995 & 125.6173 & 129.8411 & 127.8607 & 127.0213 & 127.8929 \\
\hline & 8.013 & 97.826 & 101.4431 & 104.3418 & 102.8719 & 102.5618 & 102.9049 \\
\hline & 5.993 & 72.506 & 75.33706 & 77.02617 & 76.09284 & 76.06897 & 76.11882 \\
\hline & 3.973 & 48.338 & 50.19588 & 50.98595 & 50.5133 & 50.56582 & 50.52896 \\
\hline \multirow{11}{*}{333.15} & 24.040 & 242.839 & 252.8345 & 265.6839 & 259.5303 & 251.8671 & 259.5332 \\
\hline & 22.020 & 224.425 & 234.3723 & 245.7615 & 240.4981 & 234.2006 & 240.5679 \\
\hline & 20.067 & 207.161 & 215.8794 & 225.8603 & 221.3727 & 216.3539 & 221.4786 \\
\hline & 18.047 & 188.747 & 196.0967 & 204.6345 & 200.8674 & 197.0882 & 200.9854 \\
\hline & 16.027 & 169.182 & 175.68 & 182.8025 & 179.6819 & 177.015 & 179.7921 \\
\hline & 14.007 & 149.616 & 154.6753 & 160.4283 & 157.8923 & 156.1701 & 157.9821 \\
\hline & 11.987 & 127.749 & 133.1463 & 137.5982 & 135.5974 & 134.6212 & 135.6611 \\
\hline & 9.966 & 105.882 & 111.1749 & 114.4223 & 112.9163 & 112.4723 & 112.9546 \\
\hline & 7.946 & 85.166 & 88.85869 & 91.03211 & 89.98197 & 89.86304 & 90.00016 \\
\hline & 5.993 & 63.299 & 67.06426 & 68.3602 & 67.70458 & 67.73198 & 67.7106 \\
\hline & 3.906 & 40.281 & 43.65127 & 44.22782 & 43.92035 & 43.9755 & 43.92078 \\
\hline \multirow{11}{*}{363.15} & 24.040 & 218.670 & 227.4674 & 237.9229 & 232.4172 & 227.0283 & 232.7277 \\
\hline & 22.088 & 202.558 & 211.2601 & 220.5309 & 215.8245 & 211.4446 & 216.1178 \\
\hline & 20.067 & 186.445 & 193.9769 & 202.0344 & 198.0834 & 194.6852 & 198.3424 \\
\hline & 17.980 & 169.182 & 175.5751 & 182.4016 & 179.1564 & 176.6794 & 179.3675 \\
\hline & 16.027 & 153.069 & 157.8771 & 163.5837 & 160.933 & 159.2082 & 161.0933 \\
\hline & 14.007 & 134.655 & 139.1037 & 143.6979 & 141.5992 & 140.5207 & 141.7069 \\
\hline & 11.987 & 115.090 & 119.8922 & 123.4378 & 121.8317 & 121.2511 & 121.8923 \\
\hline & 9.966 & 95.524 & 100.2885 & 102.87 & 101.7001 & 101.4656 & 101.7242 \\
\hline & 7.946 & 74.808 & 80.34766 & 82.07417 & 81.28466 & 81.25334 & 81.28522 \\
\hline & 5.993 & 56.394 & 60.81249 & 61.84254 & 61.36381 & 61.41528 & 61.35442 \\
\hline & 4.512 & 41.432 & 45.86356 & 46.46801 & 46.1824 & 46.24224 & 46.17241 \\
\hline \multirow{11}{*}{393.15} & 24.040 & 197.954 & 207.4401 & 216.1139 & 211.2069 & 207.3155 & 211.6463 \\
\hline & 22.088 & 182.992 & 192.5665 & 200.2326 & 196.0667 & 192.9535 & 196.4434 \\
\hline & 20.067 & 168.031 & 176.7583 & 183.399 & 179.9353 & 177.5635 & 180.2405 \\
\hline & 18.047 & 153.069 & 160.5257 & 166.1658 & 163.3382 & 161.627 & 163.5694 \\
\hline & 16.027 & 136.957 & 143.878 & 148.5513 & 146.294 & 145.148 & 146.4537 \\
\hline & 14.007 & 120.844 & 126.8295 & 130.5811 & 128.8292 & 128.1415 & 128.9249 \\
\hline & 11.987 & 104.731 & 109.4004 & 112.2884 & 110.9786 & 110.6362 & 111.0221 \\
\hline & 10.034 & 87.468 & 92.2155 & 94.33903 & 93.3977 & 93.28213 & 93.40498 \\
\hline & 8.013 & 70.205 & 74.1197 & 75.54289 & 74.92288 & 74.94003 & 74.90869 \\
\hline & 5.993 & 51.790 & 55.7396 & 56.57545 & 56.21509 & 56.2795 & 56.19466 \\
\hline & 4.714 & 40.281 & 43.97169 & 44.50469 & 44.27556 & 44.33777 & 44.25744 \\
\hline
\end{tabular}


Table 5. MAPEs of experimental and calculated results in the gas density prediction.

\begin{tabular}{ccccccc}
\hline MAPE & SRK & PR & LKP & BWRS & GERG-2008 & $\begin{array}{c}\text { Number of Experimental } \\
\text { Data Sets }\end{array}$ \\
\hline Sample 1 & $4.62 \%$ & $8.13 \%$ & $6.50 \%$ & $5.32 \%$ & $6.54 \%$ & 76 \\
Sample 2 & $2.92 \%$ & $6.21 \%$ & $4.62 \%$ & $3.46 \%$ & $4.66 \%$ & 77 \\
Sample 3 & $3.91 \%$ & $7.33 \%$ & $5.61 \%$ & $4.46 \%$ & $5.68 \%$ & 75 \\
Sample 4 & $4.95 \%$ & $2.14 \%$ & $3.50 \%$ & $4.59 \%$ & $3.45 \%$ & 76 \\
Sample 5 & $2.82 \%$ & $0.80 \%$ & $1.28 \%$ & $2.39 \%$ & $1.23 \%$ & 74 \\
Overall MAPE & $3.84 \%$ & $4.92 \%$ & $4.30 \%$ & $4.04 \%$ & $4.31 \%$ & - \\
\hline
\end{tabular}

\subsection{Accuracy Analysis of the Prediction Models for the Compressibility Factor}

Defined as the ratio of the actual gas volume to the ideal value, the compressibility factor, also called Z-factor, is a dimensionless parameter representing the degree to which a real gas deviates from an ideal gas. It depends on the working condition and fluid composition. Considering that the PVT relationship can be calculated when the compressibility factor is given, it is significant for prediction other gas properties.

Using the Aspen Plus software, the compressibility factors of the collected fire-flooding exhausts were predicted by employing the five prediction models under the reinjection condition. The total number of the experimental data for the five samples is 377. Table 6 shows the experimental and the calculation results of the compressibility factors for Sample 1 as an example. By comparing with experimental data, Table 7 lists the prediction accuracies for each model. The comparison result shows that, in the prediction of compressibility factor, the SRK equation performs the minimum overall MAPE, followed by the BWRS equation, while that of the LKP, GERG-2008, and PR equation stands the highest. Although the PR equation shows the highest prediction accuracy for Sample 5, that of SRK equation is maintained at a relatively high level for the five sample compositions as a whole in comparison. Therefore, it can be considered that the SRK equation is the suitable model for predicting the compressibility factor of fire-flooding exhausts during the reinjection process.

Table 6. Experimental data and calculated results of the compressibility factors for Sample 1.

\begin{tabular}{|c|c|c|c|c|c|c|c|}
\hline \multirow{2}{*}{\multicolumn{3}{|c|}{ Experimental Data }} & \multicolumn{5}{|c|}{ Calculated Results } \\
\hline & & & SRK & PR & LKP & BWRS & GERG-2008 \\
\hline$T(\mathrm{~K})$ & $p$ (MPa) & Z-Factor & \multicolumn{5}{|c|}{ Z-Factor } \\
\hline \multirow{11}{*}{303.15} & 23.937 & 1.068 & 1.023277 & 0.9685329 & 0.9907489 & 1.029885 & 0.9929652 \\
\hline & 21.924 & 1.058 & 1.009767 & 0.9578203 & 0.9780867 & 1.013005 & 0.9796722 \\
\hline & 19.911 & 1.046 & 0.9978164 & 0.948761 & 0.9674312 & 0.997747 & 0.9684879 \\
\hline & 17.897 & 1.037 & 0.9876324 & 0.9416031 & 0.9590299 & 0.9844297 & 0.9596604 \\
\hline & 15.884 & 1.028 & 0.9794267 & 0.9366147 & 0.9531164 & 0.9734118 & 0.9534156 \\
\hline & 13.982 & 1.022 & 0.9736777 & 0.9341457 & 0.9499896 & 0.9654592 & 0.9500521 \\
\hline & 11.857 & 1.016 & 0.969746 & 0.9342527 & 0.9494519 & 0.9597842 & 0.9493242 \\
\hline & 9.843 & 1.016 & 0.9685981 & 0.9374025 & 0.9518559 & 0.9578699 & 0.95161 \\
\hline & 8.054 & 1.017 & 0.9697594 & 0.9428633 & 0.9563227 & 0.9591882 & 0.9560161 \\
\hline & 6.040 & 1.023 & 0.9735473 & 0.9521314 & 0.9638359 & 0.9641602 & 0.9635069 \\
\hline & 4.027 & 1.026 & 0.9799269 & 0.964771 & 0.9737839 & 0.972774 & 0.9734824 \\
\hline \multirow{11}{*}{333.15} & 23.826 & 1.119 & 1.053305 & 1.002581 & 1.02615 & 1.057001 & 1.026104 \\
\hline & 21.812 & 1.107 & 1.040927 & 0.992916 & 1.014469 & 1.04136 & 1.01415 \\
\hline & 19.911 & 1.092 & 1.030247 & 0.984908 & 1.004752 & 1.027752 & 1.00426 \\
\hline & 17.897 & 1.080 & 1.020125 & 0.977761 & 0.995994 & 1.01479 & 0.995405 \\
\hline & 15.996 & 1.070 & 1.011791 & 0.972414 & 0.989282 & 1.004124 & 0.988676 \\
\hline & 13.982 & 1.061 & 1.00438 & 0.968403 & 0.983941 & 0.994745 & 0.983383 \\
\hline & 12.081 & 1.056 & 0.998814 & 0.966326 & 0.980644 & 0.987919 & 0.980178 \\
\hline & 9.843 & 1.053 & 0.994167 & 0.966208 & 0.979005 & 0.982693 & 0.978681 \\
\hline & 8.054 & 1.050 & 0.991999 & 0.968062 & 0.979455 & 0.980868 & 0.97925 \\
\hline & 6.040 & 1.052 & 0.991263 & 0.972347 & 0.981814 & 0.981448 & 0.981725 \\
\hline & 4.027 & 1.052 & 0.992357 & 0.97906 & 0.986085 & 0.984868 & 0.986072 \\
\hline
\end{tabular}


Table 6. Cont.

\begin{tabular}{|c|c|c|c|c|c|c|c|}
\hline \multirow{2}{*}{\multicolumn{3}{|c|}{ Experimental Data }} & \multicolumn{5}{|c|}{ Calculated Results } \\
\hline & & & SRK & PR & LKP & BWRS & GERG-2008 \\
\hline$T(\mathrm{~K})$ & $p$ (MPa) & Z-Factor & \multicolumn{5}{|c|}{ Z-Factor } \\
\hline \multirow{11}{*}{363.15} & 23.826 & 1.146 & 1.074154 & 1.027168 & 1.051283 & 1.075896 & 1.049874 \\
\hline & 21.924 & 1.133 & 1.062964 & 1.018457 & 1.040509 & 1.061792 & 1.039098 \\
\hline & 20.022 & 1.118 & 1.052476 & 1.010554 & 1.03067 & 1.048585 & 1.029326 \\
\hline & 18.009 & 1.106 & 1.042205 & 1.003162 & 1.021358 & 1.035726 & 1.020153 \\
\hline & 15.996 & 1.094 & 1.032867 & 0.99688 & 1.013273 & 1.024199 & 1.012268 \\
\hline & 13.982 & 1.086 & 1.02454 & 0.991822 & 1.006502 & 1.01419 & 1.00574 \\
\hline & 11.969 & 1.080 & 1.017298 & 0.988108 & 1.00112 & 1.00589 & 1.000624 \\
\hline & 9.955 & 1.074 & 1.011214 & 0.985859 & 0.99719 & 0.999483 & 0.996956 \\
\hline & 7.942 & 1.070 & 1.006353 & 0.985193 & 0.994758 & 0.995138 & 0.994752 \\
\hline & 5.928 & 1.064 & 1.002771 & 0.986223 & 0.993851 & 0.992989 & 0.994007 \\
\hline & 4.251 & 1.062 & 1.000795 & 0.988451 & 0.994265 & 0.992942 & 0.994485 \\
\hline \multirow{11}{*}{393.15} & 24.049 & 1.176 & 1.089354 & 1.045624 & 1.069927 & 1.090022 & 1.067705 \\
\hline & 21.924 & 1.160 & 1.077203 & 1.036135 & 1.057981 & 1.074814 & 1.055969 \\
\hline & 20.022 & 1.145 & 1.066871 & 1.028292 & 1.048042 & 1.061976 & 1.046273 \\
\hline & 18.009 & 1.133 & 1.056536 & 1.020722 & 1.038355 & 1.049295 & 1.036894 \\
\hline & 15.996 & 1.124 & 1.046874 & 1.013983 & 1.029599 & 1.037687 & 1.028482 \\
\hline & 13.982 & 1.113 & 1.037938 & 1.008155 & 1.021842 & 1.027295 & 1.021088 \\
\hline & 11.969 & 1.104 & 1.029779 & 1.003322 & 1.015149 & 1.018271 & 1.014754 \\
\hline & 9.955 & 1.097 & 1.022451 & 0.999575 & 1.00958 & 1.010764 & 1.009513 \\
\hline & 7.942 & 1.091 & 1.016004 & 0.997002 & 1.005188 & 1.004915 & 1.005386 \\
\hline & 6.040 & 1.085 & 1.010766 & 0.995733 & 1.00216 & 1.001027 & 1.002521 \\
\hline & 4.810 & 1.080 & 1.007835 & 0.995547 & 1.000793 & 0.9994 & 1.001202 \\
\hline
\end{tabular}

Table 7. MAPEs of experimental and calculated results in the compressibility factor prediction.

\begin{tabular}{ccccccc}
\hline MAPE & SRK & PR & LKP & BWRS & GERG-2008 & $\begin{array}{c}\text { Number of Experimental } \\
\text { Data Sets }\end{array}$ \\
\hline Sample 1 & $5.72 \%$ & $8.78 \%$ & $7.39 \%$ & $6.34 \%$ & $7.42 \%$ & 76 \\
Sample 2 & $9.48 \%$ & $12.35 \%$ & $11.00 \%$ & $9.94 \%$ & $11.03 \%$ & 76 \\
Sample 3 & $3.78 \%$ & $6.86 \%$ & $5.34 \%$ & $4.32 \%$ & $5.41 \%$ & 75 \\
Sample 4 & $1.92 \%$ & $4.94 \%$ & $3.44 \%$ & $2.45 \%$ & $3.49 \%$ & 76 \\
Sample 5 & $4.93 \%$ & $1.51 \%$ & $3.11 \%$ & $4.27 \%$ & $3.06 \%$ & 74 \\
Overall MAPE & $5.17 \%$ & $6.89 \%$ & $6.06 \%$ & $5.46 \%$ & $6.08 \%$ & - \\
\hline
\end{tabular}

\subsection{Accuracy Analysis of the Prediction Models for the Volumetric Coefficient}

The volumetric coefficient refers to the gas volume under the specified condition for the unit volume of gas at the standard condition. It is a function of the gas compressibility factor. Using the Aspen Plus software and the computational relation, the volumetric coefficients of the fire-flooding exhaust samples were calculated by employing the above five prediction models under the detection conditions. The total number of the experimental data for the five samples is 379 . Table 8 shows the experimental and the calculation results of Sample 1 as an example. By comparing with the experimental data, Table 9 lists the prediction accuracies for each model. The comparison results show that the model precision is greatly affected by the gas composition. Among the evaluated methods, the SRK equation performs the highest accuracy, followed by the BWRS equation, while the PR, LKP, and GERG-2008 equations bring out bigger errors. Therefore, it can be considered that the SRK equation is suitable for predicting the volumetric coefficient of fire-flooding exhausts during the reinjection process. 
Table 8. Experimental data and calculated results of the volumetric coefficient for Sample 1.

\begin{tabular}{|c|c|c|c|c|c|c|c|}
\hline \multirow{2}{*}{\multicolumn{3}{|c|}{ Experimental Data }} & \multicolumn{5}{|c|}{ Calculated Results } \\
\hline & & & SRK & PR & LKP & BWRS & GERG-2008 \\
\hline$T(\mathrm{~K})$ & $p(\mathrm{MPa})$ & $\begin{array}{l}\text { Volumetric } \\
\text { Coefficient }\end{array}$ & \multicolumn{5}{|c|}{ Volumetric Coefficient } \\
\hline \multirow{11}{*}{303.15} & 24.142 & 0.004700 & 0.0044496 & 0.0042107 & 0.0043081 & 0.0044798 & 0.004318 \\
\hline & 22.018 & 0.005036 & 0.0048105 & 0.0045625 & 0.0046594 & 0.0048266 & 0.0046671 \\
\hline & 20.106 & 0.005456 & 0.0052081 & 0.0049508 & 0.0050489 & 0.0052093 & 0.0050546 \\
\hline & 18.053 & 0.006043 & 0.0057391 & 0.0054704 & 0.0055721 & 0.0057218 & 0.0055759 \\
\hline & 16.000 & 0.006715 & 0.0064198 & 0.006138 & 0.0062464 & 0.0063813 & 0.0062485 \\
\hline & 14.018 & 0.007638 & 0.0072822 & 0.0069861 & 0.0071046 & 0.007221 & 0.0071051 \\
\hline & 12.035 & 0.008897 & 0.0084485 & 0.0081363 & 0.0082691 & 0.0083627 & 0.0082681 \\
\hline & 9.982 & 0.010743 & 0.0101717 & 0.0098408 & 0.0099932 & 0.0100593 & 0.0099907 \\
\hline & 8.071 & 0.013345 & 0.0125957 & 0.0122457 & 0.0124207 & 0.0124583 & 0.0124167 \\
\hline & 6.018 & 0.017878 & 0.0169603 & 0.0165884 & 0.0167919 & 0.0167972 & 0.0167862 \\
\hline & 4.035 & 0.026942 & 0.0254551 & 0.0250607 & 0.0252952 & 0.025269 & 0.0252873 \\
\hline \multirow{11}{*}{333.15} & 24.142 & 0.005288 & 0.005036 & 0.004792 & 0.004906 & 0.005056 & 0.004906 \\
\hline & 22.089 & 0.005791 & 0.005438 & 0.005185 & 0.005299 & 0.005442 & 0.005297 \\
\hline & 20.177 & 0.006211 & 0.005891 & 0.005629 & 0.005744 & 0.005879 & 0.005741 \\
\hline & 18.124 & 0.006882 & 0.006491 & 0.00622 & 0.006337 & 0.006459 & 0.006333 \\
\hline & 16.071 & 0.007722 & 0.007255 & 0.006972 & 0.007093 & 0.007201 & 0.007089 \\
\hline & 14.089 & 0.008729 & 0.008216 & 0.00792 & 0.008048 & 0.008138 & 0.008043 \\
\hline & 12.035 & 0.010156 & 0.00956 & 0.009249 & 0.009386 & 0.009455 & 0.009382 \\
\hline & 9.982 & 0.012170 & 0.011476 & 0.01115 & 0.011299 & 0.011344 & 0.011295 \\
\hline & 8.071 & 0.015108 & 0.01416 & 0.013818 & 0.013981 & 0.014001 & 0.013978 \\
\hline & 6.089 & 0.020144 & 0.018756 & 0.018396 & 0.018576 & 0.01857 & 0.018574 \\
\hline & 4.035 & 0.030384 & 0.02833 & 0.027949 & 0.02815 & 0.028116 & 0.02815 \\
\hline \multirow{11}{*}{363.15} & 24.142 & 0.005959 & 0.005597 & 0.005351 & 0.005478 & 0.005609 & 0.005471 \\
\hline & 22.089 & 0.006463 & 0.006049 & 0.005794 & 0.005921 & 0.006043 & 0.005913 \\
\hline & 20.106 & 0.006966 & 0.006576 & 0.006314 & 0.00644 & 0.006553 & 0.006431 \\
\hline & 18.053 & 0.007722 & 0.007251 & 0.006979 & 0.007106 & 0.007206 & 0.007097 \\
\hline & 16.142 & 0.008561 & 0.00804 & 0.007759 & 0.007887 & 0.007974 & 0.007879 \\
\hline & 14.018 & 0.009820 & 0.00918 & 0.008886 & 0.009018 & 0.009087 & 0.009011 \\
\hline & 12.035 & 0.011331 & 0.010617 & 0.010311 & 0.010447 & 0.010498 & 0.010442 \\
\hline & 10.053 & 0.013513 & 0.012635 & 0.012316 & 0.012458 & 0.012488 & 0.012455 \\
\hline & 8.000 & 0.016871 & 0.015799 & 0.015465 & 0.015616 & 0.015622 & 0.015615 \\
\hline & 6.018 & 0.022410 & 0.020929 & 0.020579 & 0.02074 & 0.020723 & 0.020743 \\
\hline & 4.389 & 0.030636 & 0.028636 & 0.028272 & 0.028443 & 0.028406 & 0.028449 \\
\hline \multirow{11}{*}{393.15} & 24.142 & 0.006715 & 0.006138 & 0.005891 & 0.006028 & 0.006142 & 0.006016 \\
\hline & 22.089 & 0.007218 & 0.006636 & 0.006382 & 0.006517 & 0.006622 & 0.006505 \\
\hline & 20.106 & 0.007806 & 0.007217 & 0.006955 & 0.007089 & 0.007184 & 0.007077 \\
\hline & 18.124 & 0.008561 & 0.00793 & 0.00766 & 0.007793 & 0.007876 & 0.007782 \\
\hline & 16.142 & 0.009484 & 0.008823 & 0.008544 & 0.008677 & 0.008747 & 0.008667 \\
\hline & 14.089 & 0.010827 & 0.01002 & 0.009731 & 0.009864 & 0.009918 & 0.009857 \\
\hline & 12.035 & 0.012506 & 0.011635 & 0.011335 & 0.011469 & 0.011505 & 0.011465 \\
\hline & 10.053 & 0.014940 & 0.013831 & 0.01352 & 0.013656 & 0.013673 & 0.013655 \\
\hline & 8.071 & 0.018549 & 0.017121 & 0.016796 & 0.016936 & 0.016933 & 0.016939 \\
\hline & 6.089 & 0.024508 & 0.022572 & 0.022234 & 0.022379 & 0.022354 & 0.022387 \\
\hline & 4.885 & 0.030636 & 0.028053 & 0.027707 & 0.027855 & 0.027816 & 0.027866 \\
\hline
\end{tabular}


Table 9. MAPEs of experimental and calculated results in the volumetric coefficient prediction.

\begin{tabular}{cclllcc}
\hline MAPE & SRK & PR & LKP & BWRS & GERG-2008 & $\begin{array}{c}\text { Number of Experimental } \\
\text { Data Sets }\end{array}$ \\
\hline Sample 1 & $6.22 \%$ & $9.28 \%$ & $7.89 \%$ & $6.83 \%$ & $7.92 \%$ & 76 \\
Sample 2 & $9.28 \%$ & $12.12 \%$ & $10.78 \%$ & $9.74 \%$ & $10.81 \%$ & 77 \\
Sample 3 & $4.08 \%$ & $7.11 \%$ & $5.61 \%$ & $4.59 \%$ & $5.67 \%$ & 76 \\
Sample 4 & $2.92 \%$ & $5.97 \%$ & $4.49 \%$ & $3.41 \%$ & $4.53 \%$ & 76 \\
Sample 5 & $5.16 \%$ & $1.74 \%$ & $3.34 \%$ & $4.49 \%$ & $3.29 \%$ & 74 \\
Overall MAPE & $5.53 \%$ & $7.24 \%$ & $6.42 \%$ & $5.81 \%$ & $6.44 \%$ & - \\
\hline
\end{tabular}

\subsection{Accuracy Analysis of the Prediction Models for Dew Point}

Forecasting dew points involves the calculation of both gas and liquid properties, including the compressibility factor, fugacity, etc. The calculation accuracy reflects the ability of each EoS in predicting phase equilibrium parameters. Using the Aspen Plus software, the dew point lines of the fire-flooding exhaust samples were calculated by employing the above five models. The total number of the experimental data for the five samples is 217 . Figures 2-6 show the experimental and predicted value of dew point temperatures under different pressures for the five samples, respectively. It can be seen that, except for the BWRS equation, the incontinuity of dew point lines occurs within some pressure range when the other four equations were adopted. According to the literature published, it stands for the non-convergence or non-solution at the specified conditions for solving the liquid-vapor equilibrium $[35,53,54]$. The case happens for both cubic and non-cubic equations, especially near the critical zone. Improvements can be done from the aspects of model description, mathematical algorithm, etc.

Meanwhile, for every model, as the pressure increases, the deviation between the experimental and calculated value increases gradually. With the non-convergence points excluded, Table 10 lists the prediction accuracy of the calculation models. It can be found that, the LKP equation performs the highest accuracy with a MAPE of $3.71 \%$, followed by SRK equation of which MAPE is $4.33 \%$. Errors brought by other equations are beyond $5 \%$. Although the prediction accuracy of the dew points through the LKP equation is slightly higher than the SRK equation, the latter has stronger computational convergence than the former over the whole pressure range. Hence, considering the prediction accuracy and computational convergence, the SRK equation is suitable for predicting the dew points of fire-flooding exhaust during the reinjection process.

Table 10. MAPEs of experimental and calculated results in the dew point prediction.

\begin{tabular}{ccccccc}
\hline MAPE & SRK & PR & LKP & BWRS & GERG-2008 & $\begin{array}{c}\text { Number of Experimental } \\
\text { Data Sets }\end{array}$ \\
\hline Sample 1 & $2.81 \%$ & $2.84 \%$ & $1.70 \%$ & $8.20 \%$ & $3.78 \%$ & 43 \\
Sample 2 & $1.56 \%$ & $2.44 \%$ & $3.80 \%$ & $6.85 \%$ & $3.02 \%$ & 43 \\
Sample 3 & $7.31 \%$ & $8.84 \%$ & $3.17 \%$ & $9.84 \%$ & $7.59 \%$ & 43 \\
Sample 4 & $3.73 \%$ & $4.51 \%$ & $4.72 \%$ & $8.68 \%$ & $3.71 \%$ & 44 \\
Sample 5 & $6.22 \%$ & $8.52 \%$ & $5.15 \%$ & $8.91 \%$ & $9.65 \%$ & 44 \\
Overall MAPE & $4.33 \%$ & $5.43 \%$ & $3.71 \%$ & $8.50 \%$ & $5.55 \%$ & - \\
\hline
\end{tabular}

\section{Results}

Comparing all the predicted data with the experimental data, the overall summary of the calculation accuracy for each EoS is shown in Table 11. 
Table 11. Summary of the precisions of the five physical property calculation methods.

\begin{tabular}{cccccc}
\hline Overall MAPE & SRK & PR & LKP & BWRS & GERG-2008 \\
\hline Gas density & $3.84 \%$ & $4.92 \%$ & $4.30 \%$ & $4.04 \%$ & $4.31 \%$ \\
Compressibility factor & $5.17 \%$ & $6.89 \%$ & $6.06 \%$ & $5.46 \%$ & $6.08 \%$ \\
Volumetric coefficient & $5.53 \%$ & $7.24 \%$ & $6.42 \%$ & $5.81 \%$ & $6.44 \%$ \\
Dew point & $4.33 \%$ & $5.43 \%$ & $3.71 \%$ & $8.50 \%$ & $5.55 \%$ \\
\hline
\end{tabular}

It can be found that, for calculating the different physical properties, the precision of the evaluated equations is uneven. The SRK equation performs well in predicting the gas densities, but the calculation of compressibility factors and volume coefficients has a notable deviation, exceeding $5 \%$. The PR equation shows good accuracy in terms of the gas density prediction, whereas the errors of the compressibility factors and volume coefficients computation happen to be around 7\%. The LKP equation has the highest precision in forecasting the dew points, but it is not accurate enough in calculating the compressibility factors and volume coefficients with the MAPE of beyond $6 \%$. The BWRS equation has good precision in forecasting the gas densities, but the biggest error of $8.50 \%$ is observed when it is used to conduct the dew point calculation. The GERG-2008 equation also achieves good performance in the gas density prediction. However, a big error of more than $6 \%$ exists for computing the compressibility factors and the volume coefficients. Hence, it is revealed that although the GERG-2008 equation is considered as the international standard model for the natural gas, it is not entirely suitable for the fire-flooding exhaust.

Above all, for the five samples of the fire-flooding exhaust tested, the SRK equation takes the minimum MAPE in predicting the properties mentioned. In terms of dew point prediction, although the accuracy of the LKP equation is slightly higher than that of SRK equation, the latter has stronger computational convergence than the former over the whole pressure range. Taking both the prediction accuracy and computational convergence into consideration, the SRK equation is recommended as the basic prediction method for the physical properties during the reinjection of the fire-flooding exhaust.

\section{Conclusions}

Accurate prediction of the physical properties with the change of working conditions is of significant importance for the design and simulation of the reinjection processes of fire-flooding exhaust. In this paper, five property calculation methods-including PR, SRK, LKP, BWRS, and GERG-2008 EoS-were evaluated in predicting the properties of the fireflooding exhaust under the conditions of reinjection process. By employing the Aspen Plus software, four properties of five representative fire-flooding exhaust compositions which collected from an oilfield in northwest China were calculated, including the gas densities, compressibility factors, volumetric coefficients, and dew point temperatures. Through a comprehensive comparison and analysis with 1351 sets of experimental detecting data, it is revealed that the SRK equation shows the best prediction performance among the five studied equations, thus it can be recommended as the basis for the property prediction in the reinjection process of the fire-flooding exhaust.

The result in this paper is helpful to select a precise property calculation method for the fire-flooding exhaust under the wide range of temperature and temperature. Thus the reinjection system can be simulated and designed in higher accuracy, which will reduce the harmful gas emission made by the in-situ combustion in a novel and efficient way. Although the compositions were collected from China, it is believed that this work can also provide reference for the study of other similar gases globally. By applying the SRK equation, the high-accuracy prediction on the physical properties and phase transition can be conducted. This is the prerequisite to carry out theoretic and applied research for the related gas. Considering the components in this study contain hydrocarbons, nitrogen, carbon dioxide, hydrogen sulfide, etc., with the increasingly higher standards on the environmental protection, the results can be also applied in the waste treatment processes. 
Since more detailed components of other countries or regions have not been found out from the published literature unfortunately, our work was based on the samples collected from Chinese oilfields. Although it is believed that the samples used in this study are representative, whether the result is suitable for other oilfields can be further evaluated by the researchers based on more local component data.

Meanwhile, the binary interaction parameters of Knapp et al. were used for the SRK equation, the PR equation, the LKP equation, and the BWRS equation. The prediction accuracy can be improved through the regression of binary parameters using more experimental data.

Finally, the experimental data in this paper were obtained without a water component. There may be trace amounts of water in the fire-flooding exhaust during the reinjection process. Considering the influence of water on gas physical properties, the prediction accuracy of cubic EoSs, virial EoSs, and GERG-2008 can be further studied based on the research results of this paper.

Author Contributions: Conceptualization, Y.W.; Methodology, Y.W. and M.C.; Validation, M.C., D.H. and S.F.; Formal analysis, Y.W. and M.C.; Resources, L.C.; Writing—original draft preparation, Y.W. and M.C.; Writing-review and editing, Y.W.; Supervision, L.C. and S.W. All authors have read and agreed to the published version of the manuscript.

Funding: This work was funded by the Natural Science Basic Research Program of Shaanxi (Program No. 2021JQ-593), and also supported by Open Fund (PLN2020-16) of State Key Laboratory of Oil and Gas Reservoir Geology and Exploitation (Southwest Petroleum University).

Institutional Review Board Statement: Not applicable.

Informed Consent Statement: Not applicable.

Data Availability Statement: Not applicable.

Conflicts of Interest: The authors declare no conflict of interest.

$\begin{array}{ll}\text { Abbreviations } \\ \text { EOS } & \text { equation of state } \\ \text { PR } & \text { Peng-Robinson } \\ \text { SRK } & \text { Soave-Redlich-Kwong } \\ \text { LKP } & \text { Lee-Kesler-Plocker } \\ \text { BWRS } & \text { Benedict-Webb-Rubin-Starling } \\ \text { PR-CPA } & \text { Peng-Robinson cubic plus association } \\ \text { PC-SAFT } & \text { perturbed chain-statistical associating fluid theory } \\ \text { NRTL } & \text { non-random two liquid } \\ \text { NIST } & \text { National Institute of Standards and Technology } \\ \text { PVT } & \text { pressure, volume, and temperature } \\ \text { LNG } & \text { liquefied natural gas } \\ \text { BOG } & \text { boil-off gas } \\ \text { HPHT } & \text { high pressure and high temperature } \\ C C & \text { correlation coefficient } \\ M S E & \text { mean squared error } \\ M A E & \text { mean absolute error } \\ M A P E & \text { mean absolute percentage error } \\ \text { RMSE } & \text { root mean square error } \\ \text { NRMSE } & \text { normalized root mean squared error } \\ M A R N E & \text { mean absolute range normalized error }\end{array}$

\section{References}

1. Le Van, S.; Chon, B.H. Chemical Flooding in Heavy-Oil Reservoirs: From Technical Investigation to Optimization Using Response Surface Methodology. Energies 2016, 9, 711. [CrossRef]

2. Alvarado, V.; Manrique, E. Enhanced Oil Recovery: An Update Review. Energies 2010, 3, 1529-1575. [CrossRef] 
3. Kar, T.; Hascakir, B. Effect of solvent type on emulsion formation in steam and solvent-steam flooding processes for heavy oil recovery. Colloids Surf. A Physicochem. Eng. Asp. 2021, 611, 125783. [CrossRef]

4. Yang, J.; Hou, J.; Qu, M.; Liang, T.; Wen, Y. Experimental study the flow behaviors and mechanisms of nitrogen and foam assisted nitrogen gas flooding in 2-D visualized fractured-vuggy model. J. Pet. Sci. Eng. 2020, 194, 107501. [CrossRef]

5. Thorne, R.J.; Sundseth, K.; Bouman, E.; Czarnowska, L.; Mathisen, A.; Skagestad, R.; Stanek, W.; Pacyna, J.M.; Pacyna, E.G. Technical and environmental viability of a European $\mathrm{CO}_{2}$ EOR system. Int. J. Greenh. Gas Control 2020, 92, 102857. [CrossRef]

6. Guan, W.; Xi, C.; Chen, Y.; Zhang, X.; Muhetar; Liang, J.; Huang, J.; Wu, J. Fire-flooding technologies in post-steam-injected heavy oil reservoirs. Pet. Explor. Dev. 2011, 38, 452-463. [CrossRef]

7. Wang, T.; Xiu, J.; Cui, Q.; Huang, L.; Ma, Y.; Yu, L. Research advances in numerical simulation of microbial enhanced oil recovery. J. Cent. South Univ. (Sci. Technol.) 2019, 50, 1474-1484. [CrossRef]

8. Yuan, S.; Jiang, H.; Yang, F.; Shi, Y.; Bai, Y.; Du, K. Research on characteristics of fire flooding zones based on core analysis. J. Pet. Sci. Eng. 2018, 170, 607-610. [CrossRef]

9. Mendoza, A.; Perozo, H.; Oliveros, D.A.; Reyes, N. Study for improving the in-situ combustion of Venezuela extra-heavy crude oil using unconventional additive. In Proceedings of the World Heavy Oil Congress 2011, Edmonton, AB, Canada, $14-17$ March 2011.

10. Feng, T.; Wu, Y.; Hu, C.; Gong, Y.; Yang, S. Technology of fire flooding process control: Application to fire flooding in a deep and thick heavy oil reservoir in China. In Proceedings of the SPE Asia Pacific Oil and Gas Conference and Exhibition, Brisbane, Australia, 23-25 October 2018. SPE-191897-MS. [CrossRef]

11. Zhao, R.; Li, B.; Yang, J.; Gao, B.; Zhang, C.; Fu, J.Y.; Wang, R. Temperature prediction via reaction heat calculation of burned pseudo-components during in-situ combustion. Fuel 2018, 214, 264-271. [CrossRef]

12. Wang, S.; Tang, L.; Carroll, J.J. A state of the art of acid gas injection and its application prospects in China. Nat. Gas Ind. 2013, 33, 105-111. [CrossRef]

13. Dong, M.; Huang, S. Flue Gas Injection for Heavy Oil Recovery. J. Can. Pet. Technol. 2002, 41, 44-50. [CrossRef]

14. Chen, D.; Zhang, Z.; Yang, J.; Ma, X.; Li, P.; Hao, X.; Guan, G. Process simulation and energy saving analysis of $\mathrm{CO}_{2}$ capture by chemical absorption method based on self-heat recuperation. J. Chem. Ind. Eng. 2019, 70, 2938. [CrossRef]

15. Hussain, A.; Hägg, M.-B. A feasibility study of $\mathrm{CO}_{2}$ capture from flue gas by a facilitated transport membrane. J. Membr. Sci. 2010, 359, 140-148. [CrossRef]

16. Aouini, I.; Ledoux, A.; Estel, L.; Mary, S.; Evrard, P.; Valognes, B. Experimental Study of Carbon Dioxide Capture from Synthetic Industrial Incinerator Flue Gas with a Pilot and Laboratory Measurements. Procedia Eng. 2012, 42, 704-720. [CrossRef]

17. Qin, H. Analysis and control measures of tail gas in the development process of the in situ combustion. Oil Gas Field Surf. Eng. 2016, 35, 102-104. [CrossRef]

18. Wang, Y.; Wang, S.; Chen, L.; Chen, L.; Wang, S. Numerical calculation and analysis on phase behavior of fireflood exhaust from HQ-1 well in Xinjiang oilfield. IOP Conf. Ser. Earth Environ. Sci. 2019, 242, 022024. [CrossRef]

19. Askari, O.; Vien, K.; Wang, Z.; Sirio, M.; Metghalchi, H. Exhaust gas recirculation effects on flame structure and laminar burning speeds of $\mathrm{H}_{2} / \mathrm{CO} /$ air flames at high pressures and temperatures. Appl. Energy 2016, 179, 451-462. [CrossRef]

20. Kang, M.S.; Hwang, J. Effect of $\mathrm{SO}_{2}$ Concentration on $\mathrm{NO}_{\mathrm{x}}$ Removal Efficiency in $\mathrm{NaOH}-B a s e d$ Wet Scrubbing. J. Korean Soc. Atmos. Environ. 2018, 34, 659-667. [CrossRef]

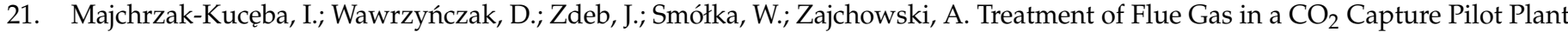
for a Commercial CFB Boiler. Energies 2021, 14, 2458. [CrossRef]

22. Razmara, N.; Kirch, A.; Meneghini, J.; Miranda, C. Efficient $\mathrm{CH}_{4} / \mathrm{CO}_{2}$ Gas Mixture Separation through Nanoporous Graphene Membrane Designs. Energies 2021, 14, 2488. [CrossRef]

23. Li, Q.; Liu, X.; Du, L.; Bai, B.; Fang, Z.; Jing, M.; Li, X. Economics of Acid Gas Injection with Comparison to Sulfur Recovery in China. Energy Procedia 2013, 37, 2505-2510. [CrossRef]

24. Li, S.; Li, Z.; Sun, X. Effect of flue gas and $\mathrm{n}$-hexane on heavy oil properties in steam flooding process. Fuel 2017, 187, 84-93. [CrossRef]

25. Wang, Y.; Wei, N.; Wan, D.; Wang, S.; Yuan, Z. Numerical Simulation for Preheating New Submarine Hot Oil Pipelines. Energies 2019, 12, 3518. [CrossRef]

26. Modekurti, S.; Eslick, J.; Omell, B.; Bhattacharyya, D.; Miller, D.; Zitney, S.E. Design, dynamic modeling, and control of a multistage $\mathrm{CO}_{2}$ compression system. Int. J. Greenh. Gas Control 2017, 62, 31-45. [CrossRef]

27. Yuan, Z.; Cui, M.; Song, R.; Xie, Y. Evaluation of prediction models for the physical parameters in natural gas liquefaction processes. J. Nat. Gas Sci. Eng. 2015, 27, 876-886. [CrossRef]

28. Zhou, J.; Chen, J.; Gao, P.; Gao, H. Wellbore flow model of acid gas reinjection. Nat. Gas Ind. 2005, 8, 76-78. [CrossRef]

29. Wang, T.; El Ahmar, E.; Coquelet, C.; Kontogeorgis, G.M. Improvement of the PR-CPA equation of state for modelling of acid gases solubilities in aqueous alkanolamine solutions. Fluid Phase Equilib. 2018, 471, 74-87. [CrossRef]

30. Pereira, V.J.; Regueira, V.B.; Costa, G.M.N.; De Melo, S.A.B.V. Modeling the Saturation Pressure of Systems Containing Crude Oils and $\mathrm{CO}_{2}$ Using the SRK Equation of State. J. Chem. Eng. Data 2019, 64, 2134-2142. [CrossRef]

31. Adom, E.; Islam, S.Z.; Ji, X. Modelling of boil-off gas in LNG tanks: A case study. Int. J. Eng. Technol. 2010, 2, $292-296$.

32. Wan, P.; Shi, P.; Dai, Y. Simulation and optimization technology of the hydrocarbons removal unit of acid gas removal. Comput. Appl. Chem. 2020, 3, 201-208. [CrossRef] 
33. Yan, W.; Varzandeh, F.; Stenby, E.H. PVT modeling of reservoir fluids using PC-SAFT EoS and Soave-BWR EoS. Fluid Phase Equilib. 2015, 386, 96-124. [CrossRef]

34. Bertini, M.; Fiaschi, D.; Manfrida, G.; Niknam, P.H.; Talluri, L. Evaluation of the property methods for pure and mixture of $\mathrm{CO}_{2}$ for power cycles analysis. Energy Convers. Manag. 2021, 245, 114568. [CrossRef]

35. Di Marcoberardino, G.; Morosini, E.; Manzolini, G. Preliminary investigation of the influence of equations of state on the performance of $\mathrm{CO}_{2}+\mathrm{C}_{6} \mathrm{~F}_{6}$ as innovative working fluid in transcritical cycles. Energy 2022, 238, 121815. [CrossRef]

36. Varzandeh, F.; Stenby, E.H.; Yan, W. Comparison of GERG-2008 and simpler EoS models in calculation of phase equilibrium and physical properties of natural gas related systems. Fluid Phase Equilib. 2017, 434, 21-43. [CrossRef]

37. Redlich, O.; Kwong, J.N.S. On the Thermodynamics of Solutions. V. An Equation of State. Fugacities of Gaseous Solutions. Chem. Rev. 1949, 44, 233-244. [CrossRef] [PubMed]

38. Soave, G. Equilibrium constants from a modified Redlich-Kwong equation of state. Chem. Eng. Sci. 1972, 27, 1197-1203. [CrossRef]

39. Zhong, J.; Zhao, X.; Li, B.; Lin, X.; Geng, Z. Calculation of material properties of SF6/CF4 gas mixture based on SRK state equation. High Voltage Appar. 2016, 52, 48-53. [CrossRef]

40. Peng, D.-Y.; Robinson, D.B. A New Two-Constant Equation of State. Ind. Eng. Chem. Fundam. 1976, 15, 59-64. [CrossRef]

41. Plocker, U.; Knapp, H.; Prausnitz, J. Calculation of High-Pressure Vapor-Liquid Equilibria from a Corresponding-States Correlation with Emphasis on Asymmetric Mixtures. Ind. Eng. Chem. Process. Des. Dev. 1978, 17, 324-332. [CrossRef]

42. Liu, L.; Liu, B.; Li, S.; Qi, J. Calculation of LNG Thermodynamic Properties. Contemp. Chem. Ind. 2010, 39, 88-90. [CrossRef]

43. Benedict, M.; Webb, G.B.; Rubin, L.C. An Empirical Equation for Thermodynamic Properties of Light Hydrocarbons and Their Mixtures, I. Methane, Ethane, Propane and n-Butane. J. Chem. Phys. 1940, 8, 334-345. [CrossRef]

44. Starling, K.E.; Powers, J.E. Enthalpy of Mixtures by Modified BWR equation. Ind. Eng. Chem. Fundam. 1970, 9, 531-537. [CrossRef]

45. Starling, K.E.; Han, M.S. Thermo data refined for LPG-14 mixtures. Hydrocarbon Process. 1972, 51, $129-132$.

46. Farzaneh-Gord, M.; Mohseni-Gharyehsafa, B.; Toikka, A.; Zvereva, I. Sensitivity of natural gas flow measurement to AGA8 or GERG2008 equation of state utilization. J. Nat. Gas Sci. Eng. 2018, 57, 305-321. [CrossRef]

47. Kunz, O.; Wagner, W. The GERG-2008 Wide-Range Equation of State for Natural Gases and Other Mixtures: An Expansion of GERG-2004. J. Chem. Eng. Data 2012, 57, 3032-3091. [CrossRef]

48. Gong, K.; Wang, Z.; Jia, Y. Generalization of thermodynamic research of LNG and other mixtures storage and transportation process. Sci. Technol. Eng. 2013, 13, 121-131, CNKI:SUN:KXJS.0.2013-35-023.

49. Renon, H. Vapor-Liquid Equilibria for Mixtures of Low Boiling Substances, Vol. VI: H. Knapp, R. Döring, L. Oellrich, V. Plöcker and J.M. Prausnitz, 1982, 9890 pp. ISBN 3-921 567-38-6, DECHEMA, Chemistry Data Series, Frankfurt am Main. Fluid Phase Equilib. 1985, 21, 174-175. [CrossRef]

50. Panapakidis, I.P.; Dagoumas, A.S. Day-ahead natural gas demand forecasting based on the combination of wavelet transform and ANFIS/genetic algorithm/neural network model. Energy 2017, 118, 231-245. [CrossRef]

51. Wei, N.; Li, C.; Peng, X.; Zeng, F.; Lu, X. Conventional models and artificial intelligence-based models for energy consumption forecasting: A review. J. Pet. Sci. Eng. 2019, 181, 106187. [CrossRef]

52. Sedaghat, M.; Kiomarsiyan, A. Applying MLP-ANN as a novel and accurate method to estimate gas density. Pet. Sci. Technol. 2019, 37, 2128-2133. [CrossRef]

53. Panah, H.S. Modeling binary vapor-liquid equilibrium data containing perfluorocarbons using the Peng-Robinson and the PC-SAFT equations of state. Int. J. Refrig. 2018, 85, 13-26. [CrossRef]

54. Bisotti, F.; Galeazzi, A.; Galatioto, L.; Masserdotti, F.; Bigi, A.; Gritti, P.; Manenti, F. Implementing robust thermodynamic model for reliable bubble/dew problem solution in cryogenic distillation of air separation units. Int. J. Thermofluids 2021, 10, 100083. [CrossRef] 